\title{
DEMOCRACIA DIRECTA: UN ANÁLISIS COMPARADO
}

\author{
Francisco Miro Quesade Rada
}

$\mathbf{E}$ ntiendo por democracia directa un conjunto de prácticas instituciones y politicas por la que los individuos participan en el poder politico, lo más directamente posible y con el minimo de intermediación. La democracia directa es pues más participación que intermediación.

La definición tradicional de democracia como poder del pueblo expresa esta idea. Si el pueblo tiene poder, debe de ejercerlo. Es pues la democracia directa una practica politica, una manera de conducirse en el proceso de toma de decisiones politicas. Pero esta practica politica tiene su correkato institucional. A lo largo de la historia observamos que en diversas sociedades se han creado instituciones que contribuyen a que las personas participen 10 más directamente posible en el proceso de toma de decisiones politicas. Estas instituciones son:

1. El referéndum

2. La iniciativa popular en la formación de las leyes

3. El veto popular de las leyes

4. La revocación

5. El rendimiento de cuentas

6. La teleinformática 
Desde luego cuando analizamos los sistemas politicos, no encontramos ninguno en donde haya democracia directa pura, por lo general las instituciones de la democracia directa aparecen combinadas o mezcladas con aquellas de la democracia representativa. Por estas razones se habla de democracia semidirecta.

Sin embargo en los últimos años, cuando hacemos unanálisis de los sistemas politicos $y$ de las instituciones politicas, descubrimes que la democracia directa empieza a adquirir cada vez más presencia.

También observamos que estas instituciones, no apareceno funcionan en su totalidad, en otras palabras no están universalizadas, por el contrario están en una etapa germinal.

Las instituciones que mâs presencia y aceptación tienen en los sistemas politicos y constitucionales es el referéndum y la iniciativa popular, esto no sucede con la revocación, el veto popular y el rendimiento de cuentas. En cuando a la teleinformática. llamada también teledemocracia, sólo funciona de manera experimental en aquellas sociedades en donde se ha alcanzado un alto desarrolio tecnologico en el área de las telecomuricaciones.

La revocación por ejemplo, so aplica con relativa frocuencia enaigunos estados de ta union norteamericana y está reconocids en algunas constituciones. Es muy escasa la normatividad que la regula y a veces parece ser más producto de la costumbre democrá. tica, que de la creación y normatividad juridica. El veto popular es otra institución de poco uso.

¿En qué medida la democracia directa reemplazará a la representativa?. Es una pregunta de dificil respuesta, pero pensamos que con la universalización de la informática y de la cibernelica, este reemplazo puede ser posible.

Por el momento hay una convivencia saludabie, porque ambas se retroalimentan. La democracial directa contribuye a reforzar el sistema democrático $y$ no afecta, en las condiciones actuales, a la representativa. No se trata pues de oponer o de entrentar a una democracia con ctra, sino de complementarlas, con la finalidad de -democratizar más la democracia:.

\section{EL. SISTEMA DEMOCRÁTICO}

La democracia es un sistema de valores, conductas, prácticas e instituciones. Implica la aceptación de un conjunto de caracteristicas que le son propias y que la diferencian de otros sistemas de gobierno, como son el autoritarismo y el totalitarismo.

Podemos decir que un sisterna politico es democrático, cuando en el se cumplen un conjunto de caracteristicas y principios:

1. El pincipio de la electividad

2. Pluralismo ideopolitioo y partidario

3. La altemancia en el poder y presencia de 


\section{una oposición}

4. E principio de la constitucionalidad y el respeto de las leyes

5. E principio de la participación

6. Respeto por los Derechos Humanos

7. El principio de la división de poderes

8. Control intraorgánico e interorgánico entre los poderes del Estado

9. E principio de la tolerancia.

Todos estos principios y practicas deben estar interrelacionados.

Pero cabe advertir que la falta de algunos no significa que un sistema politico ya no sea democrático, puede existir una democracia sollida y estable, sin instituciones de la democracia directa; pero una democracia sera mayor si la participación popular directa es tolerada y reconocida.

La importancia de la democracia directa, no consiste sollo en que el pueblo podra tener más poder o podrá compartido con las elites politicas, sino en que contribuye a superar e! elifismo, incluyendo su forma caudilista, la meritocracia y la desinformación politica, que son delormaciones que se presentanen el sistema democrático.

Por ejemplo si democratizamos la estructura interna de los partidos politicos, con una mayor participacion de la militancia, e incluso si los abrimos màs hacia la comunidad, irá desapareciendo el elitismo en su torma de caudilismo, porque por esta democratización las elites partidarias circularain más graclas a un sistema de competencias peribdicas.

Si ampliamos la base participativa de fos ciudadanos en la estructura administrativa del Estado, podremos superar o al menos. controlar los excesos de ta tecnoburocracia que se sustenta en la meritocracia.
Si creamos el libre acceso de los ciudadanos a cualquier tipo de información, podrán participar en la sociedad politica con mayor conocimiento, tanto de los problemas cotidianos, como de los mencs frecuentes. Si universalizamos la informacidon la posibilidad de participar en una pluralidad de decisiones serd mayor. De lo contrario, mientras el acceso a la información sea solo un recurso de los gobernantes, la mayoria seguirá desinformada, por ende marginada, en gran medida de las grandes decisiones politicas. Habra pues que superar el elitismo, la meritocracia y la desinformación y esto es posible en la medida que funcionen adecuadamente y de una manera universal las insthucicnes de la democracia directa.

\section{EL. ANÁLISIS COMPARADO}

En la medida que hay instituciones de la democracia directa en diversos paises, nuestro andilisis comparado, se reducirá el ámbito latinoamericano. Dentro de este contexto hemos considerado algunas instituciones tipo, que están sancionadas por al Derecho Constitucional.

\section{EL.REFERENDUMEN URUGUAY}

Unuguay es el único pais de América Latina que ha utilizado con cierta frecuencia y continuidad las consultas populares incorporando el plebiscito $y$ el releréndum en su ordenamiento constitucional.

La actual Constitución sancionada por la Asamblea Generał del 24 de agosto de 1966 y aprobada en la consulta popular del 27 de noviembre del mismo an̂o, incorpora en Giversos articulos el releréndum y la iniciativa popular, pero también el plebiscito. Los unuguayos, al menos de acuerdo a su 
Constitución y a la práctica, no distinguen oon claridad entre reteréndum y plebiscito. No obstante, hay algunos criterios de aplicación que pueden permitir cierta distinción. Por ejempla, la Constitución deberá ser aprobada por plebiscito; en cambio, cuando se somete a consulta popular una ley, se habla de referéndum.

Una particularidad del sistema politico uruguayo ha sido su estabilidad, que se rompió con el advenimiento del llamado bordaberrismo y el posterior golpe de Estado de 1973 sumiendoal pais de los "charrúas" en una crisis politica, producto de un conjunto de factores en donde el terrorismo de los tupamaros atecto visiblemente la estabilidad democrática.

Con anterioridad a esta époce critica, Uruguay se ha debatido desde comienzos del siglo entre dos formas de gobiemo democráticas: la *directorial", llamada también ocolegiadas o "colectiva $y$ el opresidencialistar.

El gobiemo *colegiado* se implantó por influencia de Jasé Batlle y Ordónez, quien después de haber ejercido la primera magistratura, entre 1903 y 1907 vijó a Suiza, en donde tuvo la cportunidad de conocer el funcionamiento de la democracia directa en este pais. Impresionado por los efectos positivos y de la estabilidad de la democracia entre los helveticos, la propone a su regreso en 1922, planteando el reemplazo del presidencialismo por un ejecutivo colegiado. El colegiado uruguayo funciono desde 1918 hasta 1934, fecha en ta que se regresó nuevamente al presidenciallsmo.

Luego de un periodo más o menos largo y de ciertas modilicaciones constitucionales, uno de los discipulos de Batile el prolesor
Terra, consiguib que se adoptara nuevamente el sistema colegiado, con un ejecutivo direclorial y sus correspondientes ministros.

Kart Loewenstein y André Hauriou coinciden al sostener que el sistema implantado por Terra se parece más al incorporado en las constituciones francesas de la Tercera y Cuarta República que al modelo suizo establecido en la Constitución de 1874.

Ambas constituciones francesas establecieron una estructura dualista del Poder Ejecutivo. La función ejecutiva quedo dividida en dos órgenos gubemamentales diferentes: el Presidente de la República y el gobiemo o gabinete.

El Gobierno Ejecutivo Colegiado unuguayo fue un intento de limitar al máximo el prosidencialismo e incorporas a la oposición en la responsabilidad gubemamental: uno de los factores que permitió la buena marcha de esta institución se debió, en cierta medida, a la existencia del bipartidismo.

Comase ha indicado, el colegiado unguayo duró hasta las elecciones de 1966, que puso en el gobiemo al General Gestido del Partido Colorado, lecha en que se regresa al presidencialismo *frenado*.

En Uruguay se han realizado relerendums desde 1917. A partir de esta fecha se convocaron otros en $1934,1942,1951$. $1966,1982,1989$ y 1993.

En el releréndum de 1982 la dictadura militar sometio a consulta popular una nueva Constitucion para remplazar a la de 1966. El pueblo unuguayo se pronunció en contra de este proyecto constitucional. Esta decisión popular fue definitiva porque, por un ledo, el pueblo unuguayo rechazó la dictadura 
militar y, por el otro, mantuvo vigente la Constitución de 1966 que habia-sido aprobada por plebiscito.

Los militares respetaron la decisión del pueblo y convocaron a elecciones presidenciales y parlamentarias en 1984.

Cuando en 1985 se instaurd definitivamente la democracia en Uruguay, el Parlamento aprobo una ley de amnistia para todos los presos politicos, reduciendo incluso, las penas impuestas a los acusados de pertenecer al movimiento subversivo *Tuparnaros". Esta ley exchryó en forma expresa a los integrantes de las fuerzas armadas, siendo algunos de sus miembros acusados de violar los Darechos Humanos durante el gobiemo de tacto.

Con el fin de eliminar en forma definitiva los inconvenientes acaecidos hasta ese momen10, ol gobiemo presento al Parlamento un proyecto de ley por el que se establece la suspension de todos los procesos iniciados contra los integrantes de las FFAA. acusados de violar los Derechos Humanos.

Este proyecto fue aprobadio con al voto de la mayoria de los integrantes del Partido Nacional, partido opositor mayoritario que consideró que era la única vie para lograr la paz entre todos los uruguayos.

De esa forma la mayoria pariamentaria aprobs la ley $N^{*} 15.848$, denominada "Ley de Caducidad de Pretensión Punitiva del Estado- o =Ley de Caducidads.

Esta iniciativa no fue compartida por un sector del Partido Nacional y toda ta izquiencla, quieries unidos en la llamada Comisión Nacional Pro Reteróndum iniciaron un movimiento para derogar ta mencionada ley.
Para ello se puso en juego los mecanismos previstos en la Constitución uruguaya, la que en su articulo 79 establece:

-El veinticinco por ciento del total de inscritos habilitados para votar, podrá interponer. dentro del aho de su promulgación, el recurso de referéndum contra las leyes y ejercer el derecho de iniciativa ante el Poder Legislativo: .

Reunidas las firmas minimas necosarias, se dio lugar al recurso de referéndum contra la Ley de Caducidad de Pretensión Punitiva del Estado; fijándose la fecha del 16 de abril de 1989 , para que los ciudadanos uruguayos en forma libre y democrática maniliesten su opinión sobre si se mantiene o se deroga la aludida norma. De acuerdo a lo establecido por la Corte Electoral, ef mecanismo aplicado en esa circunstancia consistib en la utilización de dos boletas, una de color amarillo para quienes manifestaron su interés en mantener la vigencia de la norma y la boleta verde para quienesse expresaron por la derogatoria de la relerida ley.

En este referéndum el pueblo se pronunció por la continuidad de ta Ley de Caducidad (ver cuadro).

Se ha mencionado que el articulo 79 incorpora el referéndum y la iniciativa, pero el referéndum y el plobiscito se oncuentran también en otros articulos. El inclso $* \mathrm{c} *$ del art. 322, que trata sobre las facultades de la Corte Electoral, señala en su parte final que esta corte es ajuez de las elecciones de todos los carpos electivos, de los actos de plebiscito y referándum *.

El 8ft. 331, incorpora el referendum constitucional para los posibles casos de reforma total o perclat pero con el nombre de plebiscito La decision piebiscitaria tigura en 
los incisos *a*, "b*, "c*, "dv y "e*, que fijan las modalidades y mecanismos de la consulta popular.

Tambièn el inciso wa* de las Disposiciones Transitorias y Especiales, reconoce el referéndum constituyente, pero utilizando siempre el término plebiscito. Este inciso dice:

«A) Si el plebiscito fuera proclamado afirmativo por resolución firme de la Corte Electoral, la presente retorma entrará en vigor con la fuerza obligatoria a partir del 15 de tebrero de 1967\%.

Como se puede apreciar, en el Uruguay existen las siguientes clases de consulta popular:

1. Referéndum Constituyente

2. Heferéndum Constitucional

3. Iniciativa popular para solicitar referóndum.
El referéndum uruguayo es abrogativo, ello quiere decir que a través del mismo se puede derogar una ley. También cabe precisar que en Uruguay no existe ni revocación ni rendimienio de cuentas.

\section{GUATEMALA}

La Constitución guatemalteca, reconoce la consulta popular, pero no utiliza los términos referéndum y plebiscito.

Cuando se trata de decisiones politicas de especial trascendencia, estas deberan ser sometidas a procedimientos consultivos de todos los ciudadanos (art, 173). Esta consulta la convocará el Tribunal Supremo Electoral.

La iniciativa para la consulta es potestativa del presidente, el Congreso y de los ciudadanos, pero no hay en Guatemala iniciativa popular en la formación de las leyes.

\section{REFERÉNDUM EN URUGUAY SOBRE LEY DE CADUCIDAD DE PRETENSIÓN PUNTTIVA DEL ESTADO RESULTADOS DE TODO EL PAIS}

CIRCUITOS ESCRUTADOS; 7,069

FALTANESCRUTAR: 3

Votos emitidos \%

$1^{\prime} 016,547$

$52.52 \%$

VOTOS AMAFILLOS

777,580

$40.18 \%$

25,897

$1.33 \%$

VOTOSENBLANCO

SOBRES GMOUAS ANULADAS

EN SUTOTALIDAD

TOTAL DE VOTOSESCRUTADOS
101,801

$5.26 \%$

1993,201
$84.74 \%$ 
tampoco revocación, ni rendimiento de cuentas. La iniciativa popular para proponer reformas de la Constitución, está prevista en el inc.d del art. 277 que dice: -El pueblo mediante petición dirigida al Congreso de la República, por lo menos de cinco mil ciudadanos debidamente empadronados por el Registro de ciudadanos*.

Tambien se reconoce la consulta populat cuando se reatizan reformas, que sean planteadas por el Congreso. Las mismas que entrarán en vigencia cuando sean ratificadas mediante consulta popular (art. 200).

De acuerdo a estas normas la Constitución guatemalteca, reconoce la consulta popular para la reforma constitucional, la que es de especial trascendencia politica y la iniciativa dependerá de la decisión del Presidente y del Congreso. Por otro lado se reconcce la iniciativa popular para la reforma constitucional.

\section{COSTA RICA}

La Constitución de este pais soblo reconoce la consulta popular, que denomina plebiscito, para la creación de nuevas prowincias. Este plebiscito, deberá sr ordenado por la Asamblea Nacional, para que se celebre en la provincia o provincias que soporten la desmembracion. No hay otras instituciones de la democracia directa.

\section{CHILE}

En el caso de Chile, la consulta poputar que se denomina plebiscito, procede para la reforma de la Constitucion. Esta consulta es posible sólo para el caso de que ef Presidente de la Republica rechazara totaimente el proyecto de reforma aprobado por el Congreso y si este insistiere en su totalidad por las dos terceras partes de cada Cámara. Si se produjera este caso, el Presidente deberá aprobar el proyecto, salvo que decidiera someter el texto a plebiscito.

No hay en Chile iniciativa popular para la reforma constitucional ni para la formación de las leyes. Cabe resaltar, que también pueden ser sometidas a plebiscito, aquellas normas del proyecto en las cuales el Congreso haya insistido para su reforma. En este caso cada una de las cuestiones en desacuerdo serán consultadas por separado (art. 118). No hay veto popular de las leyes, revocación ni rendimiento de cuentas en la Constitución chilena.

\section{COLOMBIA}

La Constitución colombiana es pródiga en instituciones de la democracia directa. Estos están reconocidos en el Titulo IV de la Carta Magna, relativa a la participación democratica y los partidos politicos.

Prácticamente reconoce casi todas las instituciones de la democracia directa: e! voto, plebiscito, referendum, consuita populas, cabildo abierto, iniclativa legislativa, revocatoria del mandato (art. 103). Y establece que serán regulados por ley.

El Presidente de la República, previo concepto favorable del Congreso, podra realizar consultas al pueblo, cuando se trate de temas de trascendencia nacional. Hay pues referéndum autoritativo, constitucional e iniciafiva popular para la reforma constitucional. La Constitución podra ser reformada por el Congreso, por una Asamblea Constituyente, o por el pueblo mediante referéndum (art. 374). 
El pueblo puede presentar proyectos de ley, que la Constitución colombiana denomina "proyectos de acto legislativon.

Un número equivalente, al cinco por ciento del censo electoral vigente, tienen esta facultad.

Si el proyecto de reforma presentado por los ciudadanos es aprobado por la mayoría de ambas cámaras, el Congreso convocará a referéndum para que el pueblo docida si se convoca una Asamblea Constituyente. Esta convocatoria se realizará sł una tercera parte de los electores aprueba la Constitución elaborada por la Asambiea. Cabe destacar dos actos importantes:

1. El reconocimiento de la iniciativa popular y la consulta previa a la posible conformación de la Asamblea Constitución a la Asamblea Constituyente.

2. Instalación de la Asamblea Constituyente en caso de que se produzca la aprobación popular.

Este mecanismo condiciona la tormación de una Asamblea Constituyente, previa consulta popular, asi se le consulta primero al pueblo y despues se toma la decisión gubernamental, segùn ei resullado de la volación (arts. 375 y 376 ).

También pueden someterse a referóndum, las reformas constitucionales aprobados por el Congreso, cuando se refiere a los Derechcs fundamentales $\mathrm{y}$ sus garantias, a los procedimientos de participación popular o al Congreso (art. 377).

Cabe destacar que ya sea por iniciativa del gobierno o de los ciudadanos, el Congreso mediante tey, que requiere la aprobación do la mayoria, podaí someter a referéndum un proyecto de reforma constitucional que el mismo Congreso incorpore a la ley, En este caso, no es necesaria la convocatoria a unB Asamblea Constituyente.

Se establece la inconstitucionalidad de actos legislativos, referéndum, ta consulta popular y la convocatoria a la Asamblea Constituyente, cuando se violan los requisitos establecidos para la reforma constitucional (art. 379).

Se reconoce la iniciativa popular en la formación de las leyes (art. 155), los ciudadanos que presenten proyectos de ley. tendrán derecho a designar un vocera qüe debera ser oido por las Camaras en todas las etapas del tramite. Esta presencia del vocero es una particularidad de la Constitución colombiana, que no la tiene ninguna de las cuestiones aqui estudiadas.

El derechio a la participación cuddadana es muy amplio. El elector colombiano puede participar en la conformación, ejercicio y control del poder politica. Aqui se expresa normativamente uno de los grandes principios de la democracia directa, la posibildad de los cludadanos de ejercer el poder con el minimo de intermediación (art. 40).

En la Constitución colombiana se combinan todas las formas posibles de democracia directa y aunque no se sanciona, por ejerrplo qué autoridedes pueden ser revocadas, so entiende que la ley regulara of funcionamiento de asta institución.

\section{BRASIL}

Como la Colombia, ta Constituolón brasileña incorpora casi todas las instituoiones de la democracia directa: plebiscito, referéndum e 
iniciativo popular (art. 14).

Es la iniciativa popular la que más resulta en este texto. Hay iniciativa para la tormación de las leyes (art. 61 inciso 2 del mismo articulo). De acuerdo a este inciso el $1 \%$ del electorado nacional tiene derecho de iniciativa. El proyecto de ley debe presentarse a la Camara de Diputados, el electorado debe pertenecer por lo menos a cinco Estados y con no menos de tres décimos de electores de cada uno de ellos.

En materia municipal, el $5 \%$ de los electores pueden presentar proyectos de ley especificos a los gobiemos locales (art, 29 inc.XI), a diferencia de otras instituciones, en donde, por lo general, quien convoca a la consulta popular es el Presidente de la República, en este caso esta facultad recae en el Congreso Nacional (art. 48 inc. XV).

En el maroo de las disposiciones iransitorias. la Constitución establece que habra un ple. biscito el 7 de Setiembre de 1993, para que el puebio se pronuncie sobre una república o una monarcuia constitucional (art. 2).

La consulta, se adelantó al 23 de Abril y la mayoria del pueblo se pronuncio a favor de la forma republicana de gobierno y tambien del modelo presidencialista, que tue controntado con el parlamentario. Los resultados fueron:
1. Presidencialismo $57 \%$
2. Parlamentarismo $25 \%$
3. Monarquia Constitucional; $12 \%$

DATO:Agnicla of jorsan CFF.

\section{PARAGUAY}

La Constitución guarant, reconoce el referêndum legislativo, que podrả o no ser vinculante. Se reglamentará por ley su funcianamiento (art. 120). También se indica que materias no podrán ser sometidas a referendum.

1. Relaciones intemacicnales, tratados, convenios o acuerdos internacionales.

2. Expropiaciones.

3. Delensa nacional.

4. Limitación de la propieclad inmobiliaria.

5. Sistemas tributarios, monetarios y bancarios, ia contratación de empréstios. Presupuesto general de la Nación.

6. Elecciones nacionales, departamentales y municipales (art, 121).

Hay iniciativa popular en la formación de las leyes y se establece que tanto la formalidad y el número de electores necesarios para suscribir una iniciativa, será establecido por ley (art, 22).

Hay iniciativa popular para la reforma Constitucional, esta puede ser solicitada por 30 mil electores (art. 288), No se establece si una reforma total o parcial de la Constitución se deba someter a referéndum.

\section{CONSTITUCION DE PANAMA}

La Constitución panamena, reconoce el referéndum para la retorma constitucional (art. 308) y de forma especial para los tratedos y convenios relativos al canal, que luego de ser aprobados por el órgano legslativo, deberán ser sometidas a consulta popular (referéndumi) (art. 310).

No hay iniciativa popular para la reforma constitucional ni para la formación de las leyes, pero si a nivel municigal, también se reconoce el referéndum a nivel de Consejos (arts. 235 y 236 ). 


\section{VENEZUEL_A}

En la Constitución de este pais se establece la iniciativa popular en la formación de las leyes, fienen derecho a ella un número no menor de veinte mil electores (inc. 5 art. 165). Sin embargo no hay iniciativa popular para la reforma constitucional, pero si referéndum constítucional (art.246 inc.4).

\section{ECUADOR}

En la Sección VI, *De los Derechos Politicos"i, en la Constitución ecuatorlana se reconoce que los ciudadanos tienen derecho a:

\section{a. Presentar proyectos de ley.}

b. A ser consultados.

c. De fiscalizar los actos de los órganos pùbli$\cos$ (arts. 32 y 35 ).

Hay derecho de iniclativa popular para reformar la Constitución, así como para la reforma y expedición de leyes (arts. 68 y $149)$.

El Presidente de la República puede convocar y someter a consulta popular tas cuestiones que a su fuicio sean de trascendental importancia para el Estado. Esta es una facultad presidencial importante y que se asemeje al releréndum francés. La consulta popular que nace de la iniciativa presidencial, se puede ejercer principalmente en los casos siguientes:

a. Proyectos de reforma constitucional.

b. Aprobación y ratificación de tratados y acuerdos internacionales, que hubieron sido rechazados por el Congreso, plenario de las comiciones legislativas o por al propio Presidente (inc. 0 art.79).
Del análisis comparativo relativos a los textos constitucionales, solo en dos casos se pueden someter a referéndum tratados y convenios intemacionales, son los de Ecuador y Panama.

El articulo 149 combina la iniciativa popular para la reforma constitucional con la consulta popular. No dice el nimero de ciudadanos que pueden presentar una iniciativa de reforma, pero si precisa los casos en que habral consulta popular:

a Cuando el proyecto de reforma propuesto por iniciativa del Presidente de la República hubiera sido rechazado total o parcialmente por el Congreso Nacional.

b. Cuando el proyecto de retorma aprobado por el Congreso Nacional hubiera obtenido dictamen total o parcialmente desfavorable del Presidente de la República.

La norma es importante, porque en caso de contlicto de fipo legislativo entre los poderes del Estado, el pucblo docidira la controversia a través de la consuita popular.

\section{CONSTITUCION CUBANA}

La Constitución de este pais, reconoce todas las instituciones de la democracia directa. salvo of veto popular, en este sentido es tan integral como la Constitución de Colombia, aunque de rógimen politico distinto,

Toda autoridad elegida, tiene el deber de rendir cuentas de $\$ \mathrm{u}$ acluación ante los electores y estos a revocarlos cuando no justiliquen la conlianza depositada en los cludadanos (inc, $\mathrm{C}$ art. 66).

La Asamblea Nacional Popular, organo supremo del Estado, esta facultada para convocar a releréndum, no solo en los casos que prevee la Constitucion, sino cuando lo 
considere pertinente. Los diputados de esta Asamblea deben rendir cuenta y pueden ser revocados, una ley fijará la modalidad del rendimiento de cuantas y de la revocación. (inc. $U$ art. 73 , arts. 82 y 83 ).

Hay iniciativa popular en la formación de las leyes, la pueden ejercer desde $10 \mathrm{mil}$ ciudadanos con capacidad electoral (inc. $g$ art. 86)

La revocatoria y el rendimiento de cuentas está previsto, en las asambleas provinciales y municipales (inc. d, h, art 105 y arts.112113). Los jueces de los Tribunales Populares son elegidos y pueden ser revocados por el pueblo, pues este los elige a través de una asamblea y son estas asambleas que tienen el derecho a la revocatoria, además están obligados a rendir cuenta de su gestión (art. $128-129$ ).

La reforma totsi de te Constifución requiere ser aprobada por reteréndum, pero no asi la reforma parcial (art. 141). No hay iniciativa popular para la reforma constitucional.

Si hacemos uns comparación del derecho do revocatoria, en el caso cubano no hay limite, pues las diputados de la Asamblea Nacional Popular pueden ser revocados, a diferencia del caso establecido en el proyecto de Constitución peruana en donde la revocatoria se aplica a nivel de los gobiemos locales y jueces de paz, asi como, si lo establece la ley, a los jueces de primera instancia, pero no alcanzaria a los congresistas.

La Constitución colombiana reconoce las instituciones de la democracia directa, pero no fija los casos de revocatoria que debe ser sancionado por ley especial, es otra diferencia que encontramos con el caso de is revocatoria cubana.

Más allá de las consideraciones ideológicas y del sistema politico-económico, se puede afirmar que en materia de participación popular directa la Constitución cubana es la mas completa de todas las estudiadas en este trabajo.

Pero no es exacto atimar que la democracia directa, es una caracteristica de los regimenes socialistas. Como se puede apreciar existe en sistemas politicos republicanos liberales o mixtos, no sólo de latinoamericana, sino de Europa, norteamérica (referéndum locales y estuduales) y el famoso recall, que alcanza no sólo a las autoridades estuduales y locales de la unión americana, sino incluso a los funcionario de la administración pública estadual y local. Finalmente hay en algunos paises asiáticos como la República de China en Taiwan, que reconocen el referéndum, la iniciativa popular y la revocación y Corea del Sur, que reconoce el referéndum para la enmienda constitucional.

\section{CONSTITUCIÓN DE NICARAGUA}

Aunque la Constitución nicaragūense señala que este pais es una República democrática. participativa y representativa no se reconoce taxativamente las instituciones de la democracia directa. Sin embargo, en el Capitulo VII, relativo al Poder Electoral, se precisa que a este poder del Estado, entre otras facultades le corresponde la organización, dirección y vigilancia de elecciones, plebiscito y referéndum (art 167).

No hay iniciativa popular en la formación de las leyes, ni para la reforma constitucional, no hay referéndum constitucional, revocación y rendimiento de cuentas. Pero ya que la ley 
reconoce la facultad de organización, dirección y vigilancia de plebiscitos y referéndum, se entiende que estas pueden realizarse y que su mecanismo debe ser regulado por ley (art. 172 inc. 1).

\section{AVANCE DEMOCRÁTICO}

Tomando como modelos, las consttuciones aqui analizadas (Uruguay, Guatemala, Costa Rica, Chile, Colombia, Brasil, Paraguay. Ecuador, Panamá, Cuba y Nicaragua). observamos un adelanto en materia de participación popular. Salvo el caso de las Constituciones de Costa Rica y Nicaragua, en donde la primera limita la consulta popular a nivel provincial y la segunda la considera como una posibilidad, las otras constituciones en mayor o menor medida, reconocen normativamente, una demanda y expresian de los pueblos lalinoamericanos, por participar mas en la estructura del poder.

De todas las Constitudiones analizadas, son la colombiana y la cubana las más universales, porque reconoce la totalidad de lasinstituciones de la democracia directa.

Las Constituciones de Unuguay, Guatemaik, Chile, Colombia, Panama, Ecuador, Cuba, Paraguay y Venezuela sancionan ef referéndum para los casos de reforma constitucional. Lo mismo sucede con la iniciativa popular en la formación de las leyes y la reforma constitucional. que funcionan en Uruguay, Guatemaia, (solo para la reforma constitucional) Colombia, Brasil (sólo formación de leyes). Paraguay, Cuba (scio para la formación de las leyes). Venezuela (solo para la formación de las leyes).
LA DEMOCRACIA DIRECTA EN EL ANTEPROYECTO DE LA CONSTITUCION PERUANA

El proyecto de la Constitución peruana, que será sometida a referéndum el 31 de octubre, es muy amplio en materia de democracia directa. Si el pueblo peruano lo aprobara, la Constitución peruana futura cortaria con una pluralidad de instituciones de la democracia directa, aunque con algunas limitaciones. Cabe hacer una atingencia, porque estas instituciones pasarian a un segundo plano, por la tendencia reeleccionista existente en el proyecto, que significa un clarisimo desbalance del poder, que beneficia al Presidente de la Republica y disminuye las facultades del Congreso.

Analizando el proyecto, se reconoce el derecho a participar en la vida politica, social, económica y cultural. En este contexto se incluye la revocación, iniciativa logislativa y referéndum (inc. 17 art. 2).

El derecho a participar también está reconocido en el ant. 31 y se incluye además de las instifuciones sehalsdos en el inc. 17 art. 2, la acción de rendición de cuentas, asi como el derecho y el deber de los vecinos para participar en el gobiemo municipal.

Indica el proyecto que puoden ser scmetidos. a referéndum:

a La raforma total o parciat de ta Constitución. b. La aprobación de normas con rango de ley. c.Las ordenanzas municipales.

d. Las materias relativos al proceso de descentralización (art, 32).

Por consiguiente se sanciona, el referénduin constitucional, legislativo, local y regional. Pero tambièn se pone limites a la consulta 
popular, esta no procederá si a través de ella se pretende suprimit o disminuir los derechos fundamentales. Tampoco podrá ser sometido a referéndum normas tributarias y presupuestales, ni los tratados internacionales en vigor (art. 32).

Se reconoce el derecho de iniclativa para la formación de las leyes (art. 107). Hay iniciativa popular para la reforma de la Constitución (art. 206).

El proyocto no fija ni número ni porcentaje para la iniciativa popular en la formación de las leyes, sólo se indica que se adecuará a lo que establece la ley. En cuanto a la iniciativa popular para la reforma constitucional, se indica que el $0.3 \%$ puede presentar proyectos de reforma.

Hay tambien iniciativa popular para presentar acción de inconstitucionalidad. La pueden hacer 5 mil ciudadanos, pero si se trata de una ordenanza municipal la iniciativa puede nacer del $1 \%$ de los ciudadanos del respectivo ámbito terntorial siempre que el porcentaje no exceda el número de firmas del $1 \%$ (art. 203).

El reforéndum rogional, está vinculado a ta iniciativa popular vecinal. De acuerdo al art. 190, wlas regiones se constituyen por iniciativa y mandato de las poblaciones pertenecientes a uno o más departamentos colindantes. Las provincias y los distritos contiguos pueden asimismo integrarse 0 cambiar de circunscripción.. Para ambos casos habrá referéndum.

La revocatoria popular del mandato, como se ha indicado figura en el anteproyecto pero con limitaciones, es sólo aplicable a las autoridades municipabes alcaldes y regidores (art. 191). Cabbe ta elección popular on el nombramiento y en la revocatoria de los magistrados (inc. 17 art. 139), la ley fipard el mecanismo.

Los jueces de paz podrán ser elegidos y la ley puede establecer la elección de los jueces de primera instancia (art. 152). Se entiende que los jueces alegidos también podrán ser revocados.

Pero así como el pueblo peruano podrá revocar a los alcaldes, regidores, jueces de paz y potencialmente si la ley lo establece a los jueces de primera instancia, no se fija la revocatoria del Presidente, aunque una interpretación extensiva del art. 31, que reconoce la revocación de las autoridades doja abierta esta posibilidad. En cuanto a los congresistas, la revocación popular de ellos no sería posible si nos atenemos al art. 134, relativo a la facultad del Presidente para disolver el Congreso. En este articulo se establece que fuera de la disolución *no hay otras formas de revocatoria del mandato parlamentario* desvirtuando asi to estipulado, de manera genérica en el art. 31 .

Finaimente la décimo quinta disposición transitoria, se precisa que la Constitución entre en vigencia, de acuerdo al resultado del referéndum regulado por ley constitucional.

SOCIEDAD CIVIL $Y$ SOCIEDAD POLITICA

El análisis comparado de los textos aquí estudiados y del proyecto constitucional peruano, se desprende que las diversas estructuras normativas reflejan un conjunto de demandas populares para participar en la estructura del poder.

Cabe precisar, que las leyes referentes a las 
instituciones de la democracia directa; varian según cada realidad politica ynormativa.

En algunas constituciones se reconoce la consulta popular, en sus modalidades de releréndum y plebiscito, la iniciativa popular, en algunos casos para la formación de leyes y en otros para la reforma tolal oparcial de la Constitución.

La revocación está reconocida en las Constituciones colombiana, cubana $y$ en al proyecto peruano. La diferencia es que mientras en la colombiana no se precisa en que casos habrá revocación, en el proyecto peruano y en la Constitución cubana si existe esa precisión. Si bien en estos textos hay normas que reconocen la totalidad de las instituciones de la democracia cirecta, su funcionamiento o se deja a regulación legal o se limita para casos especificos.

No obstante aunque no hay normas que acojan la integridad de las instituciones de la democracia directa, o que en otros casos, al acogerlas so limitan, podemos atirmar que hay un avance en este sentido $y$ lo hay porque los ciudadanos podraln contar con mecanismos constitucionales y legales para aplicar y ejercer la democracia directa. De esta manora se disminuye la brecha entre el poder de la sociedad civa y de la politica.

Gracias a estas instlucianes los cludadanos de muchas sociedades latinoamericanos tienen la potencialidad de ejercer poder, de esta manera la estructura jufídica contribuye a reforzar el principio que la democracia es poder del pueblo. La universalización de la democracia directa, en cuanto a su posible aplicación integral,es una tendencia del proceso de demoeratización mundial y es cuestión de esperar que esta tendencie se consolide en un futuro proximo. De esta manera se empezara a superar algunas deformaciones de la democracia representafiva en América Latina, cuales son el elitismo en su forma de caudillismo, la meritocracia y la desintormación. 